\title{
Green tea extract catechin improves cardiac function in pediatric cardiomyopathy patients with diastolic dysfunction
}


Ira J. Gelb ${ }^{5}$, Xupei Huang ${ }^{5^{*}}$ and Jie Tian ${ }^{1,2,3,4^{*}}$

\begin{abstract}
Background: Our previous studies have demonstrated that $\mathrm{Ca}^{2+}$ desensitizing catechin could correct diastolic dysfunction in experimental animals with restrictive cardiomyopathy. In this study, it is aimed to assess the effects of green tea extract catechin on cardiac function and other clinical features in pediatric patients with cardiomyopathies.

Methods: Twelve pediatric cardiomyopathy patients with diastolic dysfunction were enrolled for the study. Echocardiography, ECG, and laboratory tests were performed before and after the catechin administration for 12 months. Comparison has been made in these patients before and after the treatment with catechin. Next Generation Sequencing was conducted to find out the potential causative gene variants in all patients.

Results: A significant decrease of isovolumetric relaxation time ( $115 \pm 46$ vs $100 \pm 42 \mathrm{~ms}, P=0.047$ at 6 months; $115 \pm 46$ vs $94 \pm 30 \mathrm{~ms}, P=0.033$ at 12 months), an increase of left ventricle end diastolic volume ( $40 \pm 28 \mathrm{vs} 53 \pm 28 \mathrm{ml}$, $P=0.028$ at 6 months; $40 \pm 28$ vs $48 \pm 33 \mathrm{ml}, P=0.011$ at 12 months) and stroke volume ( $25 \pm 16$ vs $32 \pm 17 \mathrm{ml}$, $P=0.022$ at 6 months; $25 \pm 16$ vs $30 \pm 17 \mathrm{ml}, P=0.021$ at 12 months) were observed with echocardiography in these patients 6-month after the treatment with catechin. Ejection fraction, left ventricular wall thickness, biatrial dimension remained unchanged. No significant side effects were observed in the patients tested.
\end{abstract}

Conclusions: This study indicates that $\mathrm{Ca}^{2+}$ desensitizing green tea extract catechin, is helpful in correcting the impaired relaxation in pediatric cardiomyopathy patients with diastolic dysfunction.

Keywords: Hypertrophic cardiomyopathy, Restrictive cardiomyopathy, Diastolic dysfunction, Green tea extract catechin

\section{Introduction}

Cardiomyopathy is a common heart disease in children that leads to cardiac dysfunction. Among three major types of cardiomyopathies, hypertrophic cardiomyopathy $(\mathrm{HCM})$, dilated cardiomyopathy (DCM) and restrictive cardiomyopathy (RCM), HCM and RCM share a common pathological feature, i.e. diastolic dysfunction

\footnotetext{
* Correspondence: xhuang@health.fau.edu; jietian@cqmu.edu.cn

${ }^{5}$ Charlie E. Schmidt College of Medicine, Florida Atlantic University, 777 Glades Road, Boca Raton, FL 33431, USA

'Department of Cardiology, Children's Hospital of Chongqing Medical University, 136 Zhongshan Er Road, Yu Zhong District, Chongqing 400014, China

Full list of author information is available at the end of the article
}

whereas the main manifestation in DCM is systolic dysfunction [1]. In addition, HCM is most likely responsible for sudden cardiac death in the young [2, 3]. Although RCM is the least common, accounting for approximately $5 \%$ of the total pediatric cardiomyopathies, it has a very poor prognosis with about $50 \%$ deaths 2 years after diagnosis [4]. Except for cardiac transplantation, there have been no effective treatments for cardiomyopathy patients with diastolic dysfunction since its mechanisms are still unknown [5-7].

Recently, several laboratories including ours have demonstrated that cardiac myofibril hypersensitivity to $\mathrm{Ca}^{2+}$ is one of key factors resulting in an impaired relaxation

(C) The Author(s). 2019 Open Access This article is distributed under the terms of the Creative Commons Attribution 4.0 International License (http://creativecommons.org/licenses/by/4.0/), which permits unrestricted use, distribution, and 
in myocardial cells [8]. Using transgenic mouse model of cardiomyopathy, we have for the first time elucidated the relationship between $\mathrm{Ca}^{2+}$ hypersensitivity caused by myofibril protein mutations and the following diastolic dysfunction in the heart [8]. Furthermore, we have confirmed that desensitization, either using a transgenic molecule [9] or green tea extract catechin [8], is a useful tool to correct diastolic dysfunction caused by $\mathrm{Ca}^{2+}$ hypersensitivity in cardiomyopathy. Besides, the same process has been observed in HCM mouse model [10]. Experiments in vivo have indicated that calcium desensitizing catechin can interact with cardiac troponin-C to reduce myofilament $\mathrm{Ca}^{2+}$ hypersensitivity [11]. Due to its properties, catechin has been used to improve impaired heart relaxation and diastolic dysfunction in HCM or RCM $[8,10,11]$. In the present study, we have tried to confirm the therapeutic effects of green tea extract catechin on diastolic dysfunction in pediatric cardiomyopathy patients by comparing the cardiac function before and after the treatment with catechin.

\section{Materials and methods Study subjects}

Fourteen patients were admitted to Children's Hospital of Chongqing Medical University (Chongqing, China) from October 2015 to January 2017 due to HCM or RCM. Eligible patients were $\leq 18$ years of age, were diagnosis as HCM or RCM, and had evidence of diastolic dysfunction confirmed by echocardiography and clinical manifestations. Diagnostic criteria for HCM are: left ventricular hypertrophy with wall thickness $\geq 2$ standard deviations above the mean $(\mathrm{z}$ score $\geq 2)$ for age, sex, or body size, and absence of defined metabolic or hemodynamic causes such as metabolic disorders, congenital heart disease, hypertension, or exposure to drugs known to cause cardiac hypertrophy [12-14]. Diagnostic criteria for RCM are: dilated atria, evidence of diastolic dysfunction with normal or nearly normal left ventricular systolic function, no evidence of significant left ventricular hypertrophy or dilation, and absence of congenital, valvular, or pericardial diseases $[15,16]$. Finally, two patients were excluded due to the diagnosis of Pompe disease by genotyping and protein analysis and a total of 12 patients were enrolled in this study. Clinical data including medical history (age at admission, gender, weight, height, family history and clinical symptoms), physical signs, results of the diagnostic examinations (laboratory tests, ECG, echocardiography, chest X-ray, abdominal ultrasonography and cardiac magnetic resonance imaging) and treatments were collected and recorded. Written informed consent was obtained from legal guardians of all participating patients.

All participating patients were orally administrated with green tea extract catechin on their own or their legal guardian's initiative. Green tea (Camillia sinensis) contains health-promoting polyphenol compounds like epigallocatechin-3-gallate (EGCG). Decaffeinated Mega Green Tea Extract is manufactured by Life Extension Inc. (Life Extension Inc., Fort Lauderdale, FL, USA) and it contains more of these potent compounds than several cups of green tea in a convenient, once-daily, decaffeinated supplement ( $325 \mathrm{mg}$ EGCG/capsule). The initial dose of catechin was one capsule/day (about $15 \mathrm{mg} / \mathrm{kg}$ daily) and added up to three capsules/day (about $50 \mathrm{mg} /$ $\mathrm{kg}$ daily) in 3 months after catechin initial administration [8]. The half-life of EGCG is about 13-14 h [17]. All patients were administrated with green tea catechin for 12 months. In addition, all patients received routine treatment (for example, diuretics, beta-blockers, calcium channel blocking drugs, beta-adrenergic blocking agents, and angiotensin-converting enzyme inhibitors (ACEI), etc.) in accordance with the guideline for the treatment of HCM or RCM [13, 18]. Follow-up investigation was carried out by self-comparison between before and after the catechin administration. Echocardiography, laboratory tests and ECG were performed before and after the treatment of catechin.

\section{Echocardiography}

Transthoracic echocardiography measurements were performed with an ultrasound diagnostic system (IE33, Philips Inc., Amsterdam, Netherlands) by two experienced sonographers who were blinded about all other clinical data and were conducted according to the recommendations by American Society of Echocardiography. Heart rate and blood pressure were measured and recorded while the echocardiography was performed. Systolic and diastolic functions were obtained from M-mode and pulse-wave Doppler imaging. Under short-axis view, thicknesses of interventricular septum (IVS) and left ventricular (LV) posterior wall were determined in late diastole using M-mode imaging, and under four-chamber view, bi-atrial size was scaled as well. Pulmonary arterial pressure (PAP) was estimated by measuring right ventricle systolic pressure (RVSP) using tricuspid regurgitation velocity. The cardiac diastolic function and mitral blood inflow were detected using the pulse-wave Doppler. In addition, the E/A ratio (E wave, early ventricular filling; A wave, late ventricular filling) and isovolumetric relaxation time (IVRT) were measured as well. Left ventricular diastolic dysfunction was defined as IVRT $<40$ or $>80 \mathrm{~ms}$ or mitral E/A $<$ 1 or $>2$. Data analysis was carried out off-line using a customized version of self-contained analytic software from ultrasonic apparatus.

\section{Laboratory tests}

Peripheral total blood was collected using tubes containing inertia separation gel and coagulants without shaking 
for laboratory analyses, including high-sensitivity troponin I (hsTnI), myoglobin (MYO), creatine kinase isoenzyme (CKMB) and brain natriuretic peptide (BNP), and alanine aminotransferase (ALT), aspertate aminotransferase (AST), lactate dehydrogenase (LDH) and gamma-glutamyl transpeptidase (GGT) of hepatic function, and blood urea nitrogen (BUN), creatinine (CREA), uric acid (URCA) of renal function. All tests were conducted by Clinical Laboratory Center of Children's Hospital of Chongqing Medical University (Chongqing, China).

\section{Genetic tests}

Peripheral blood samples from all patients and their family were collected using tubes containing ethylene diamine tetra-acetate for Next Generation Sequencing (Beijing, JinZhun, Gene, Technology, Co, Ltd., China) and Sanger Validation, respectively. Subsequently, the pedigree of pathogenic or likely pathogenic mutations was processed to analyze genotypes and phenotypes of the diseases.

\section{Statistical analysis}

Categorical variables were presented as absolute number and percent. Continuous data were presented as mean \pm SD. All data analyses were performed with the use of SPSS (version 22.0, IBM Corporation, Armonk, New York, USA). Differences were compared by the method of Wilcoxon matched-pairs signed-rank test, which between nonparametric, continuous data detected at study inclusion and at 6-month, and at study inclusion and 12-month follow-up. Statistical significance was considered when $P$-value was less than 0.05 .

\section{Results}

\section{Patients and characteristics}

Twelve pediatric cardiomyopathy patients with diastolic dysfunction were included (five HCM and seven RCM, age ranges from 0.8 to 14.2 years). During the study, three patients died of sudden death and heart failure were terminated from the study. The remaining patients continued the whole study and no case withdrawal of the catechin administration during the whole study period. No significant complains or side effects were recorded or observed in these patients after administration of catechin. All patients but two have an obvious family history. The main clinical data and general conditions of all enrolled patients are listed in Table 1.

According to New York Heart Association (NYHA) heart failure classification criteria (Additional file 1: Table S6) [19], the remaining nine subjects all showed a significant improvement in cardiac function after the administration of catechin (heart failure levels in these patients were changed from Class III to II or from Class
Table 1 General characteristics and manifestation of the tested patients

\begin{tabular}{ll}
\hline & All patients \\
\hline Age (years) & $6.8 \pm 5.1$ \\
Gender: male/female & $8 / 4$ \\
Body weight $(\mathrm{kg})$ & $21.4 \pm 11.4$ \\
Height (cm) & $113.2 \pm 33.7$ \\
BMI (kg/m ${ }^{2}$ ) & $16.1 \pm 3.1$ \\
Diagnosis & \\
HCM & 5 \\
RCM & 7 \\
Family history & 2 \\
Symptoms & \\
Exercise intolerance & 12 \\
Syncope & 3 \\
Signs & \\
Cardiomegaly & 12 \\
Hepatomegaly & 9 \\
Edema & 6 \\
Ascites & 3 \\
Patients with gene mutation & 9 \\
\hline
\end{tabular}

Notes: $B M I$ body mass index, $H C M$ hypertrophic cardiomyopathy, $R C M$ restrictive cardiomyopathy. Continuous data are presented as mean $\pm S D$ and categorical variables are presented as number (percent)

IV to III after the administration of catechin). The follow-up time was arranged from 4 to 27 months (mean: 16 months) after the treatment. Cardiac function changes based on NYHA classification in the subjects before and after the catechin administration are shown in Table 2. No significant alterations in 12-leads ECG (heart rate, P, P-R, QRS, QT, QTc) were observed in all patients receiving the daily catechin administration (Additional file 1: Table S1).

\section{Echocardiography analysis}

Mean IVS thickness and LV posterior wall thickness in HCM patients, and mean dimension of left and right atria in RCM patients remained unchanged after the catechin administration (Additional file 1: Table S2-3 and Additional file 2: Figure S1).

Left ventricle end systolic dimension (LVESD, $20 \pm 8$ vs $21 \pm 7 \mathrm{~mm}, P=0.778$ at 6 months after catechin treatment; $20 \pm 8$ vs $21 \pm 8 \mathrm{~mm}, P=1$ at 12 months after catechin treatment), left ventricle end diastolic dimension (LVEDD, $31 \pm 9$ vs $34 \pm 8 \mathrm{~mm}, P=0.139$ at 6 months after catechin treatment; $31 \pm 9$ vs $32 \pm 9 \mathrm{~mm}, P=0.343$ at 12 months after catechin treatment), and left ventricle end systolic volume (LVESV, $16 \pm 14$ vs $18 \pm 12 \mathrm{~mm}, P=0.959$ at 6 months after catechin treatment; $16 \pm 14$ vs $19 \pm 17 \mathrm{~mm}$; $P=0.953$ at 12 months after catechin treatment) remained unchanged after catechin administration. Left ventricle 
Table 2 Genetic analysis, changes of NYHA class and prognosis before and after the catechin administration

\begin{tabular}{|c|c|c|c|c|c|c|c|c|}
\hline \multirow[t]{2}{*}{ NO. } & \multirow[t]{2}{*}{ Diagnosis } & \multirow[t]{2}{*}{ Gene (site) } & \multirow[t]{2}{*}{ Amino acid (clinical significance) } & \multirow[t]{2}{*}{ Carrier } & \multicolumn{2}{|l|}{ NYHA class } & \multirow{2}{*}{$\begin{array}{l}\text { Follow- } \\
\text { up } \\
\text { (months) }\end{array}$} & \multirow[t]{2}{*}{ Prognosis } \\
\hline & & & & & Pre-catechin & Post-catechin & & \\
\hline 1 & $\mathrm{HCM}$ & MYH7 (761C > A) & Ala254Glu (VUS) & None $^{b}$ & III & $\|$ & 7 & Died (SD) \\
\hline 2 & $\mathrm{HCM}$ & MYH7 (2464A > G) & Met822Val (Pathogenic) & None & III & $\|$ & 27 & Alive \\
\hline 3 & $\mathrm{HCM}$ & $\begin{array}{l}\text { MYH6 }(3640 \mathrm{C}>\mathrm{T}) \\
\text { RAF1 }(775 \mathrm{~T}>\mathrm{A})\end{array}$ & Arg1214Trp (VUS) Ser259Thr (Pathogenic) & $\begin{array}{l}\text { Mother } \\
\text { None }\end{array}$ & III & $\|$ & 24 & Alive \\
\hline 4 & $\mathrm{HCM}$ & $\begin{array}{l}\text { TPM1 }(900-4 G>A) \\
\text { RAF1 }(770 C>T)\end{array}$ & Splicing (VUS)Ser257Leu (Pathogenic) & $\begin{array}{l}\text { Mother } \\
\text { None }\end{array}$ & IV & IV & 4 & Died (HF) \\
\hline 5 & $\mathrm{HCM}$ & NEXN $(835 C>T)$ & Arg279Cys (VUS) & Father & III & $\|$ & 12 & Alive \\
\hline 6 & $\mathrm{RCM}$ & TNNI3 $(574 C>$ T) & Arg192Cys (Pathogenic) & None & IV & $\|$ & 24 & Alive \\
\hline 7 & $\mathrm{RCM}$ & $\begin{array}{l}\text { PKP2 }(2246 C>A) \\
\text { TNNI3 }(575 G>A)\end{array}$ & $\begin{array}{l}\text { Ala749Asp (Pathogenic) } \\
\text { Arg192His (Pathogenic) }\end{array}$ & None None & III & $\|$ & 16 & Alive \\
\hline 8 & $\mathrm{RCM}$ & $\begin{array}{l}\operatorname{DSP}(4943 \mathrm{~A}>\mathrm{G}) \\
\operatorname{DSP}(6223 \mathrm{C}>\mathrm{T}) \\
\text { ILK }(707 \mathrm{~A}>\mathrm{G})\end{array}$ & $\begin{array}{l}\text { Gln1648Arg (VUS) } \\
\text { Arg2075Trp (VUS) } \\
\text { Asn236Ser (VUS) }\end{array}$ & $\begin{array}{l}\text { Father } \\
\text { Mother } \\
\text { Mother }\end{array}$ & IV & IV & 4 & Died (HF) \\
\hline 9 & $\mathrm{RCM}$ & MYH7 $(3854-5 \mathrm{C}>\mathrm{T})$ & Splicing (VUS) & None & III & $\|$ & 21 & Alive \\
\hline 10 & RCM & Undetected $^{a}$ & Undetected & / & IV & III & 27 & Alive \\
\hline 11 & $\mathrm{RCM}$ & Undetected & Undetected & / & III & $\|$ & 14 & Alive \\
\hline 12 & $\mathrm{RCM}$ & Undetected & Undetected & / & III & $\|$ & 13 & Alive \\
\hline
\end{tabular}

Notes: DSP desmoplakin, HCM hypertrophic cardiomyopathy, HF heart failure, ILK integrin linked kinase, MYH6 alpha-myosin heavy chain, $M Y H 7$ beta-myosin heavy chain, NYHA New York Heart Association, NEXN nexilin F-actin binding protein, PKP2 plakophilin, RAF1 Raf-1 proto-oncogene, serine/threonine kinase, RCM restrictive cardiomyopathy, SD sudden death, TNNI3 isoform of troponin I, TPM1 tropomyosin alpha-1 chain, VUS variants of uncertain significance. ${ }^{\text {a }}$ There are no variants detected in patients. ${ }^{b}$ There are no carriers found in patients' family

end diastolic volume (LVEDV, $40 \pm 28$ vs $53 \pm 28 \mathrm{ml}, P=$ 0.028 at 6 months; $40 \pm 28$ vs $48 \pm 33 \mathrm{ml}, P=0.011$ at 12 months) was increased by $17.1 \%$ in most patients after catechin administration for 6 months and by $17.0 \%$ after catechin administration for 12 months. A significant improvement of stroke volume (SV) by $14.9 \%$ in most patients was observed after 6-month catechin administration, and by $23.0 \%$ in all patients after 12 -month catechin treatment. However, ejection fraction (EF) and fractional shortening (FS) of LV remained stable before and after catechin administration. The E/A ratio $(1.3 \pm 0.7$ vs $1.3 \pm 0.7, P=$ 0.674 ) remained unchanged in the patients after 6-month catechin treatment. An improvement of the E/A ratio (1.3 \pm 0.7 vs $1.7 \pm 0.6, P=0.018$ ) was observed in the patients after 12-month catechin treatment. A significant decrease of IVRT was observed after catechin administration for 6 months or 12 months. PAP calculated by RVSP remained unchanged, along with three patients having pulmonary arterial hypertension. Heart rate and blood pressure remained changeless in the patients tested during the study. In addition, five patients with a longer term of follow up (2127 months) showed a significant reduction of IVRT in echocardiography analysis. Cardiac functions measured with echocardiography are exhibited in Table 3 and Fig. 1.

\section{Laboratory analysis}

A decrease of BNP levels was observed in eight patients after 6-month treatment of catechin. This decrease continued in seven patients 12 months after the treatment (Additional file 2: Figure S2). Mean levels of hsTnI, $\mathrm{MYO}$ and CKMB in the patients remained unchanged in the whole study. Results of cardiac markers and BNP are illustrated in Additional file 1: Table S4. Hepatic functions evaluated by ALT, AST, GGT and LDH, and renal functions presented by BUN, CREA and URCA remained unchanged in the patients before and after catechin administration (Additional file 1: Table S5).

\section{Genetic analysis}

Genetic analysis of all patients is shown in Table 2 and Fig. 2. Of twelve patients, nine $(58.3 \%)$ patients were carriers of gene variants inherited from parents or spontaneously. Of three dead patients, all carried gene mutations. Among them, two carried multigene mutations. Of nine survived patients, four patients had single-gene mutations and three patients had no definite variants. In total, 14 different variants were found, including six pathogenic variants (which have been reported associated with cardiomyopathy) and eight uncertain-significance variants. Among five HCM patients, the variant of beta-myosin heavy chain (MYH7) was detected in two HCM patients. However, the $M Y H 7$ Ala254Glu (c.761C > A) mutation has not been reported so far in human. The other two HCM patients had multigene mutations and shared Raf-1 proto-oncogene, serine/threonine kinase (RAF1) gene variant (c.775 T > 
Table 3 Cardiac function measured with echocardiography

\begin{tabular}{|c|c|c|c|c|c|}
\hline Parameter & Study inclusion $(n=12)$ & 6 months after study start $(n=10)$ & $P$-value ${ }^{*}$ & 12 months after study start $(n=9)$ & $P$-value \\
\hline $\mathrm{HR}(\mathrm{bpm})$ & $93 \pm 26$ & $91 \pm 18$ & ns & $86 \pm 19$ & ns \\
\hline Systolic BP (mmHg) & $96 \pm 18$ & $104 \pm 12$ & ns & $97 \pm 16$ & ns \\
\hline Diastolic BP (mmHg) & $59 \pm 12$ & $60 \pm 5$ & ns & $57 \pm 15$ & ns \\
\hline $\operatorname{LVESD}(\mathrm{mm})$ & $20 \pm 8$ & $21 \pm 7$ & ns & $21 \pm 8$ & ns \\
\hline LVEDD (mm) & $31 \pm 9$ & $34 \pm 8$ & ns & $32 \pm 9$ & ns \\
\hline LVESV (ml) & $16 \pm 14$ & $18 \pm 12$ & ns & $19 \pm 17$ & ns \\
\hline LVEDV (ml) & $40 \pm 28$ & $53 \pm 28$ & 0.028 & $48 \pm 33$ & 0.011 \\
\hline SV (ml) & $25 \pm 16$ & $32 \pm 17$ & 0.022 & $30 \pm 17$ & 0.021 \\
\hline EF (\%) & $68 \pm 14$ & $69 \pm 14$ & ns & $67 \pm 10$ & ns \\
\hline FS (\%) & $38 \pm 13$ & $39 \pm 11$ & ns & $37 \pm 7$ & ns \\
\hline$E / A$ & $1.3 \pm 0.7$ & $1.3 \pm 0.7$ & ns & $1.7 \pm 0.6$ & 0.018 \\
\hline IVRT (ms) & $115 \pm 46$ & $100 \pm 42$ & 0.047 & $94 \pm 30$ & 0.033 \\
\hline RVSP $(\mathrm{mmHg})$ & $29 \pm 8$ & $30 \pm 6$ & ns & $30 \pm 5$ & ns \\
\hline
\end{tabular}

Notes: $A$ mitral Doppler A peak velocity, BP blood pressure, $E$ mitral Doppler E peak velocity, $E F$ ejection fraction, $F S$ fractional shortening of LV, $H R$ heart rate, IVRT isovolumetric relaxation time, $L V E D D$ left ventricle end diastolic dimension, $L V E D V$ left ventricle end diastolic volume, $L V E S D$, left ventricle end systolic dimension, LVESV left ventricle end systolic volume, ns nonsignificance, RVSP right ventricle systolic pressure, SV stroke volume. Continuous data are expressed as mean \pm SD.

${ }^{*} 6$ months after study start vs study inclusion; ${ }^{* *} 12$ months after study start vs study inclusion

A, p.Ser259Thr; c.770C > T, p.Ser257Leu). In addition, the variants of alpha-myosin heavy chain (MYH6) and tropomyosin alpha-1 chain (TPM1) were also found in two HCM patients. The variant Arg279Cys (c.835C > T) of nexilin F-actin binding protein (NEXN) was detected in one HCM patient and this is a novel variant and not reported previously. Gene mutations were detected in four RCM patients as well. Variants Arg192Cys (c.574C > T) and Arg192His (c.575G > A) of isoform of troponin I (TNNI3) both leading to amino acid changes at the point of 192 were observed in two RCM patients, respectively. Additionally, the compound heterozygous mutations (p.Gln1648Arg, c.4943A > G and p.Arg2075Trp, c.6223C $>\mathrm{T}$ ) of desmoplakin (DSP) inherited from his healthy parents was found in one RCM patient, which was extremely rare and never reported in RCM. The variants of integrin linked kinase (ILK), plakophilin 2 (PKP2) and $M Y H 7$ were also observed in RCM patients.

\section{Discussion}

In this study, we have demonstrated the beneficial effect of daily administration of catechin in cardiomyopathy patients with diastolic dysfunction. Significant increases of LVEDV and SV were observed by echocardiography examination in the patients after 6-month treatment of catechin. In addition, an improvement of the E/A ratio was also detected in the patients after 12-month catechin administration. No significant changes in cardiac structure such as the wall thickness were observed in HCM patients nor atrial size changes in RCM patients during the study period. No significant changes of pulmonary arterial pressure were observed in all patients tested. No adverse side effects (significant ECG changes or abnormal functional changes) were observed in all patient treated with catechin during the whole study.

HCM, accounting for about $42 \%$ of pediatric cardiomyopathies [20], is described as a hypertrophic heart with increased cardiac wall thickness. For the moment, there is no effective therapy for the disease. In the past, most cardiomyopathy cases were described as idiopathic cardiomyopathies and the etiologies were unknown [21, 22]. However, recent genetic and molecular studies have demonstrated that most cardiomyopathy cases have genetic defects and some are inheritable [23]. So far, the common disease genes for HCM have been summarized as those of MYH7, MYH6, TPM1 and RAF1 [24-27]. In our study, we also identified that $M Y H 7$ mutation is one of the most common gene variants in HCM cases. The two HCM patients with MYH7 mutation shared a common echocardiographic feature i.e. increased interventricular septum and diastolic dysfunction, although their mutation points were different. MYH6 mutation p.Arg1214Trp and TPM1 splicing mutation in two HCM patients inherited from their healthy mothers indicate that the variants might not cause the disease. However, RAF1 mutations p.Ser259Thr and p.Ser257Leu in these two HCM patients are pathogenic [28, 29], which was consistent with their clinical symptoms and signs. NEXN mutation p. Arg279Cys from the patient's heathy father was very unlikely to cause the disease, and the etiology in this case need further study. RCM shares a common pathological manifestation as that of HCM, i.e. diastolic dysfunction. RCM is the least common type of cardiomyopathy, but with a high mortality, in pediatric cardiomyopathy cases. RCM is characterized by a biatrial enlargement and increased myocardial stiffness with a 


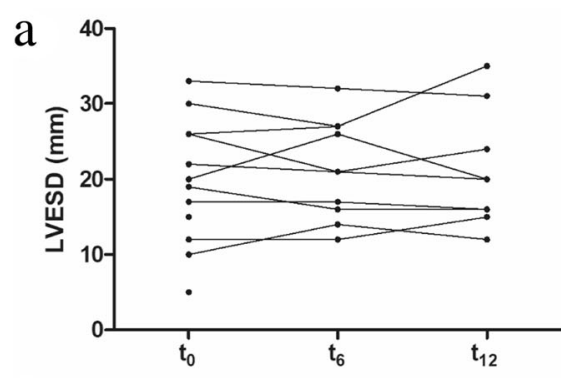

C

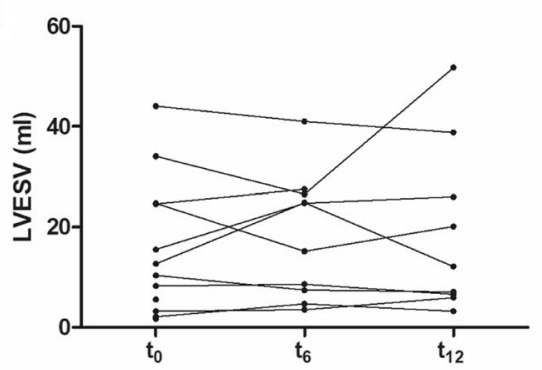

e
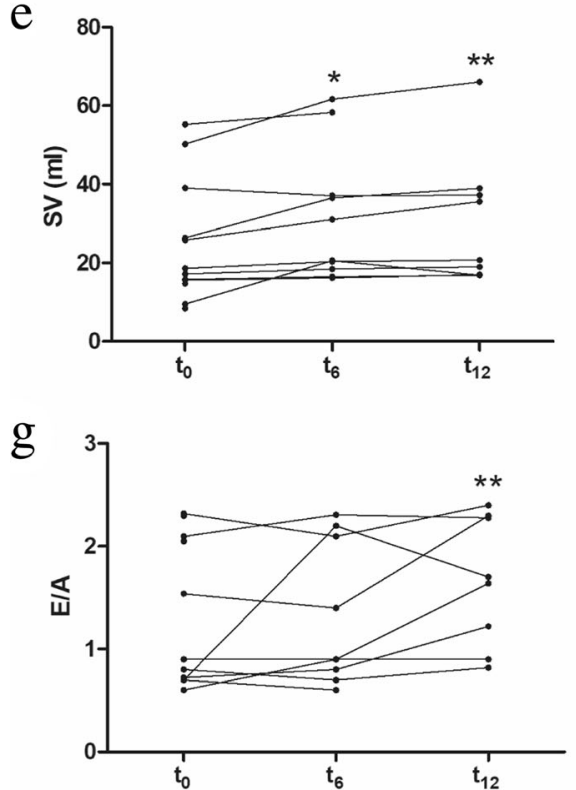
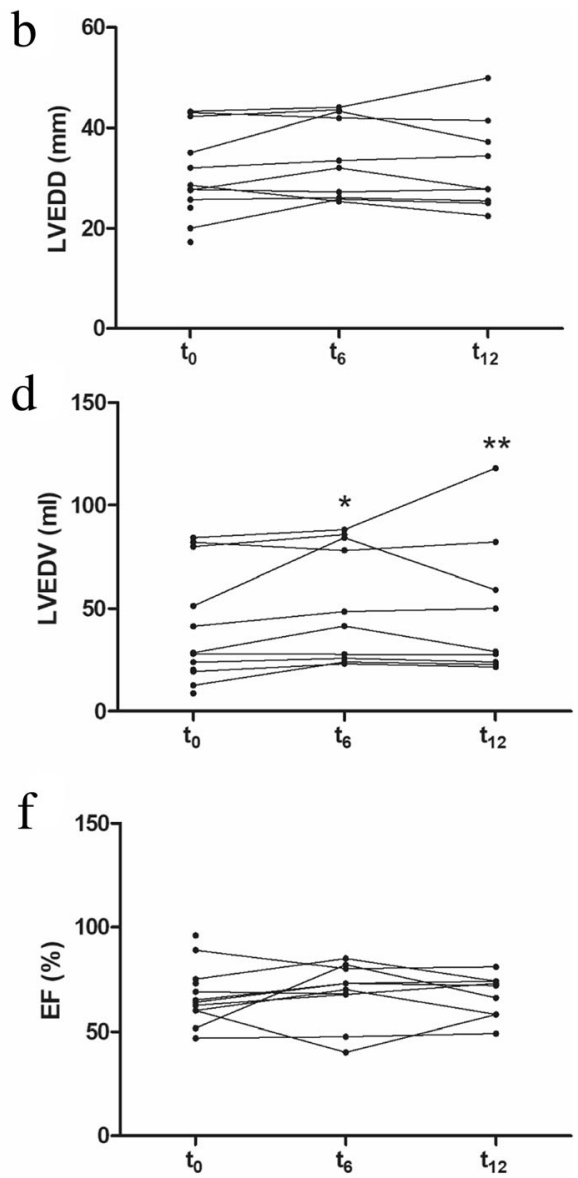

$\mathrm{h}$

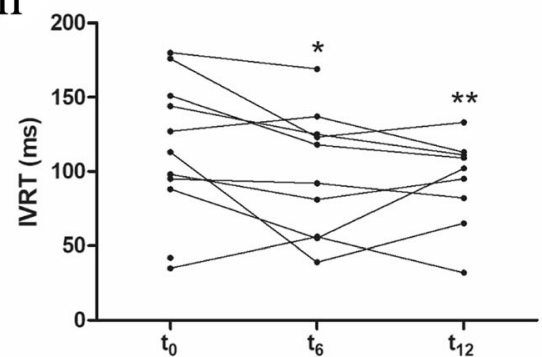

Fig. 1 Effects of $\mathrm{Ca}^{2+}$ desensitizing green tea extract catechin on cardiac function in cardiomyopathy patients with diastolic dysfunction. Various cardiac functions have been measured using echocardiography in cardiomyopathy patients before $\left(t_{0}\right)$ and after $\left(t_{6}\right.$ or $\left.t_{12}\right)$ catechin treatment: (a) left ventricular end systolic dimension (LVESD); (b) left ventricular end diastolic dimension (LVEDD); (c) left ventricular end systolic volume (LVESV); (d) left ventricular end diastolic volume (LVEDV); (e) stroke volume (SV); (f) ejection fraction (EF); (g) mitral Doppler E/A wave ratio (E/A ratio); (h) isovolumetric relaxation time (IVRT). $t_{0}$, before the administration of catechin; $t_{6}, 6$ months after the administration of catechin; $t_{12}, 12$ months after administration of catechin. ${ }^{*} P<0.05, \mathrm{t}_{6} \mathrm{vs}_{\mathrm{t}} \mathrm{t}_{0}{ }^{* *} P<0.05, \mathrm{t}_{12}$ vs $\mathrm{t}_{0}$

normal left ventricular internal dimension [22, 30]. Like HCM, most RCM cases have been described as idiopathic RCM in the previous studies, however, some sarcomere gene mutations have been reported that are associated with the development of RCM [31]. In this study, of seven RCM patients, myocardial gene mutations were detected in four patients. Among them, the TNNI3 mutation leading acidic changes at the point of
192 was found in two patients confirming that TNNI3 mutation is indeed a pathogenic cause for RCM [31-34]. In addition, one RCM patient with TNNI3 mutation also carried a pathogenic PKP2 mutation p.Ala749Asp [35], and her clinical manifestations were more serious than the patient who carries only single TNNI3 mutation. DSP mutation, being associated with arrhythmogenic right ventricular cardiomyopathy, was detected as well 


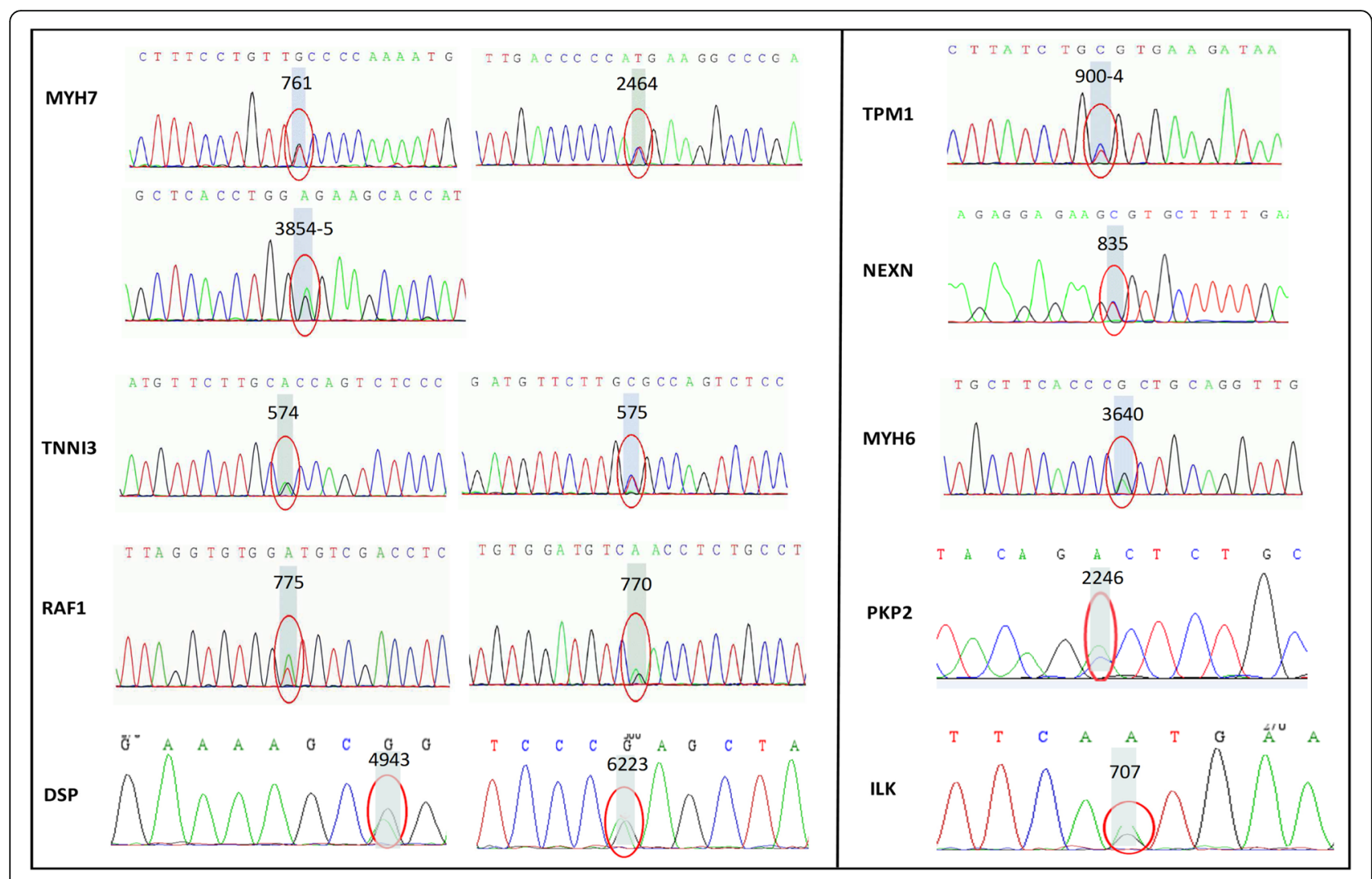

Fig. 2 Sanger validation of the mutation sites in pediatric cardiomyopathy patients. DSP, desmoplakin; HCM, hypertrophic cardiomyopathy; HF, heart failure; ILK, integrin linked kinase; MYH6, alpha-myosin heavy chain; MYH7, beta-myosin heavy chain; NYHA, New York Heart Association; NEXN, nexilin F-actin binding protein; PKP2, plakophilin; RAF1, Raf-1 proto-oncogene, serine/threonine kinase

in one RCM patient, which is never reported in RCM cases previously. Interestingly, this patient's brother was also clinically diagnosed as RCM seven years ago (no genomic data) and died from heart failure one year later. The heterozygous mutations in DSP, inherited from his heathy parents, might be the cause of the disease, and the pathogenicity of the mutations need further study to confirm. Having combined the genotyping with phenotyping analyses in the patients of our study, we have found that patients with multigene mutations have a poorer outcome compared to those with single-gene mutations or without detectable gene mutations.

For the moment, most medications used for cardiomyopathy or diastolic dysfunction are anti-symptoms, such as diuretics and beta-blockers $[6,7,36]$. Very recently, however, several studies have demonstrated that desensitization could be useful in correcting $\mathrm{Ca}^{2+}$ hypersensitivities caused by myofibril protein mutations in various cardiomyopathies with diastolic dysfunction $[8,10,11]$. Catechin, the most abundant bioactive ingredient in green tea, has been confirmed to possess an ability of desensitizing myofilaments to $\mathrm{Ca}^{2+}$ by forming a ternary complex with the C-terminal domain of troponin $C$ and the anchoring site of troponin I [11]. In vitro assays have revealed that acute treatment with $5 \mu \mathrm{M}$ of catechin has a direct effect in myocardial cells isolated from RCM transgenic mice by reducing the affinity of TnC to $\mathrm{Ca}^{2+}$ and correcting impaired relaxation [8]. In RCM transgenic mice, a long-term treatment with catechin can improve diastolic function and reverse impaired relaxation [8]. The ability of catechin to diminish myofilament $\mathrm{Ca}^{2+}$ hypersensitivity has also been exhibited in a HCM mouse model, suggesting a therapeutic potential of this compound for treating diastolic dysfunction [10]. Other studies have shown that it can reduce left ventricular thickness and mass in patients after a daily intake of green tea over 12 months [37-39].

In the present study, the significant correction of clinical manifestations and cardiac dysfunction has been observed in the patients taking green tea extract catechin. Interestingly, RCM patients with a mutation of TNNI3 have a better effect in cardiac function indicated by echocardiography measurements and BNP levels. However, due to the limited patient number, more studies are needed to confirm this hypothesis. Some studies have revealed that diastolic dysfunction can reduce cardiac output evaluated by stroke volume without much changes in EF in diastolic heart failure patients, 
i.e. heart failure with preserved ejection fraction (HFpEF) $[40,41]$. We further confirm that the HCM or RCM patients with diastolic dysfunction in this study have a normal or nearly normal EF. BNP, another prognostic marker for cardiac function, is associated with cardiovascular mortality and hospitalization [42, 43]. In the present study, a reduction of BNP is observed in most of the patients tested.

Regarding the safety of catechin use, we think that green tea extract catechin is safe because it is one of the daily supplements recommended for use for many years without reports of any serious side effects [44]. In this study, we have examined and measured cardiac biomarkers, cardiac electrical activities, and hepatic and renal functional indications, all of which do not show any significant changes during the whole period of the study. Our observations are consistent with the reports from the other studies [37-39].

Due to limited sample sizes, double-blind, placebo-controlled trial could not be processed for further analysis. Based on this study, we are planning to carry on a randomised, multinational, double-blind trial to enroll more patients to confirm the therapeutical effects of catechin on diastolic dysfunction in cardiomyopathy patients.

\section{Conclusions}

This study provides us with supporting evidences that green tea extract catechin can be used for cardiomyopathy patients with diastolic dysfunction due to its desensitizing effect. In addition, it is safe to use the green tea extract as a daily supplement under the doses used in this study without any obvious adverse side effects.

\section{Additional files}

Additional file 1: Table S1. Cardiac function observed with electrocardiography in patients before and after the catechin administration. Table S2. Parameters measured with echocardiography in HCM patients. Table S3. Parameters measured with echocardiography in RCM patients. Table S4. Cardiac markers and BNP analysis. Table S5. Hepatic and renal functions. Table S6. NYHA classification. (DOCX 28 kb)

Additional file 2: Figure S1. Echocardiographic changes of cardiac parameters during the study period of 6 and 12 months. Figure S2. Levels of BNP during the study period. (DOCX $259 \mathrm{~kb}$ )

\section{Abbreviations}

ACEl: Angiotensin-converting enzyme inhibitors; ALT: Alanine aminotransferase; AST: Aspertate aminotransferase; BNP: Brain natriuretic peptide; BUN: Urea nitrogen; CKMB: Creatine kinase isoenzyme; CREA: Creatinine; DCM: Dilated cardiomyopathy; DSP: Desmoplakin; EF: Ejection fraction; FS: Fractional shortening; GGT: Gamma-glutamyl transpeptidase; HCM: Hypertrophic cardiomyopathy; hsTnl: High-sensitivity troponin I; ILK: Integrin linked kinase; IVRT: Isovolumetric relaxation time; IVS: Interventricular septum; LDH: Lactate dehydrogenase; LV: Left ventricular; LVEDD: Left ventricle end diastolic dimension; LVEDV: Left ventricle end diastolic volume; LVESD: Left ventricle end systolic dimension; LVESV: Left ventricle end systolic volume; MYH6: Alpha-myosin heavy chain; MYH7: Betamyosin heavy chain; MYO: Myoglobin; NEXN: Nexilin F-actin binding protein; NYHA: New York Heart Association; PAP: Pulmonary arterial pressure;
PKP2: Plakophilin 2; RAF1: Raf-1 proto-oncogene, serine/threonine kinase; RCM: Restrictive cardiomyopathy; RVSP: Right ventricle systolic pressure; SV: Stroke volume; TNNI3: Isoform of troponin I; TPM1: Tropomyosin alpha-1 chain; URCA: Uric acid

\section{Acknowledgments \\ Echocardiographic test in this study was provided by Department of Ultrasound of Children's Hospital of Chongqing Medical University.}

\section{Funding}

This study was supported by research grants from National Natural Science Foundation of China (Grant Number: 81670212 and 81770265) and Science and Technology Foundation of Chongqing, China (Grant Number: cstc2015jcyjA10101 and cstc2016shmszx130003).

\section{Availability of data and materials}

All relevant data and materials are stored at Children's Hospital of Chongqing Medical University and can be obtained from the first author and corresponding author.

\section{Authors' contributions}

$J T, I J G$, and XPH conception and design of research; JJQ, ZLJ, and TWL performed the experiment; $L L$ and $J Z$ analyzed data; JJQ, JT, and XPH interpreted results of experiments; JJQ and JT prepared figures; JJQ and XPH drafted manuscript. All authors read and approved the final manuscript.

\section{Ethics approval and consent to participate}

This study was approved by the Institutional Review Board of Children's Hospital of Chongqing Medical University, China (Approval Notice 062/2013) and abided by the ethical principles outlined in the Declaration of Helsinki.

Consent for publication

Not applicable.

Competing interests

The authors declare that they have no competing interests.

\section{Publisher's Note}

Springer Nature remains neutral with regard to jurisdictional claims in published maps and institutional affiliations.

\section{Author details}

${ }^{1}$ Department of Cardiology, Children's Hospital of Chongqing Medical University, 136 Zhongshan Er Road, Yu Zhong District, Chongqing 400014, China. ${ }^{2}$ Ministry of Education Key Laboratory of Child Development and Disorders, Chongqing, China. ${ }^{3}$ China International Science and Technology Cooperation Base of Child Development and Critical Disorders, Chongqing, China. ${ }^{4}$ Chongqing Key Laboratory of Pediatrics, Chongqing, China. ${ }^{5}$ Charlie E. Schmidt College of Medicine, Florida Atlantic University, 777 Glades Road, Boca Raton, FL 33431, USA.

Received: 15 February 2019 Accepted: 30 April 2019

Published online: 08 May 2019

\section{References}

1. Flachskampf FA, Rensen TB, Solomon SD, Duvernoy O, Bjerner T. Cardiac imaging to evaluate LeftVentricularDiastolic function. JACC Cardiovasc Imaging. 2015;8:1071-93.

2. Wilkinson JD, Landy DC, Colan SD, Towbin JA, Sleeper LA, Orav EJ, Cox GF, Canter CE, Hsu DT, Webber SA, Lipshultz SE. The pediatric cardiomyopathy registry and heart failure: key results from the first 15 years. Heart Fail Clin. 2010;6(4):401-13.

3. Maron BJ, Haas TS, Ahluwalia A, Murphy CJ, Garberich RF. Demographics and epidemiology of sudden deaths in young competitive athletes: from the United States National Registry. Am J Med. 2016;129(11):1170-7.

4. Katritsis D, Wilmshurst PT, Wendon JA, Davies MJ, Webb-Peploe MM. Primary restrictive cardiomyopathy: clinical and pathologic characteristics. J Am Coll Cardiol. 1991;18(5):1230-5.

5. Pitt B, Pfeffer MA, Assmann SF, Boineau R, Anand IS, Claggett B, Clausell N, Desai AS, Diaz R, Fleg JL, Gordeev I, Harty B, Heitner JF, Kenwood CT, Lewis EF, O'Meara E, Probstfield JL, Shaburishvili T, Shah SJ, Solomon SD, Sweitzer 
NK, Yang S, McKinlay SM. Spironolactone for heart failure with preserved ejection fraction. NEW ENGL J MED. 2014;370(15):1383-92.

6. Russo LM, Webber SA. Idiopathic restrictive cardiomyopathy in children. HEART. 2005;91:1199-202.

7. Murtuza B, Fenton M, Burch M, Gupta A, Muthialu N. Pediatric heart transplantation for congenital and restrictive cardiomyopathy. Ann Thorac Surg. 2013;95:1675-84

8. Zhang L, Nan C, Chen Y, Tian J, Jean-Charles PY. Calcium desensitizer catechin reverses diastolic dysfunction in mice with restrictive cardiomyopathy. Arch Biochem Biophys. 2015;573:69-76.

9. Li Y, Charles PJ, Nan C, Pinto JR, Wang Y, Liang J, Wu G, Tian J, Feng H, Potter JD, Jin JP, Huang X. Correcting diastolic dysfunction by Ca2+ desensitizing troponin in a transgenic mouse model of restrictive cardiomyopathy. J Mol Cell Cardiol. 2010;49(3):402-11.

10. Friedrich FW, Flenner F, Nasib M, Eschenhagen T, Carrier L. Epigallocatechin3-Gallate accelerates relaxation and Ca2+ transient decay and desensitizes myofilaments in healthy and Mybpc3-targeted Knock-in Cardiomyopathic mice. Front Physiol. 2016;7:607.

11. Robertson IM, Li MX, Sykes BD. Solution structure of human cardiac troponin C in complex with the green tea polyphenol, (-)-epigallocatechin 3-Gallate. J Biol Chem. 2009;284(34):23012-23.

12. Colan SD, Lipshultz SE, Lowe AM, Sleeper LA, Messere J, Cox GF, Lurie PR, Orav EJ, Towbin JA. Epidemiology and cause-specific outcome of hypertrophic cardiomyopathy in children. CIRCULATION. 2007;115:773-81.

13. Gersh BJ, Maron BJ, Bonow RO, Dearani JA, Fifer MA, Link MS, Naidu SS, Nishimura RA, Harry SRO. ACCF/AHA guideline for the diagnosis and treatment of hypertrophic cardiomyopathy: executive summary: a report of the American College of Cardiology Foundation/American Heart Association Task Force on Practice Guidelines. Circulation. 2011;124:2761-2796, 2011.

14. Elliott PM, Anastasakis A, Borger MA, Borggrefe M, Cecchi F, Charron P, Hagege AA, Lafont A, Limongelli G, Mahrholdt H, McKenna WJ, Mogensen J, Nihoyannopoulos P, Nistri S, Pieper PG, Pieske B, Rapezzi C, Rutten FH, Tillmanns C, Watkins H. ESC guidelines on diagnosis and management of hypertrophic cardiomyopathy. Eur Heart J. 2014;35(39):2733-2779, 2014.

15. Rivenes SM, Kearney DL, Smith EO, Towbin JA, Denfield SW. Sudden death and cardiovascular collapse in children with restrictive cardiomyopathy. Circulation. 2000;102:876-82.

16. Walsh MA, Grenier MA, Jefferies JL, Towbin JA, Lorts A, Czosek RJ. Conduction abnormalities in pediatric patients with restrictive cardiomyopathy. Circ Heart Fail. 2012;5(2):267-73.

17. Abe O, Ono T, Sato H, Müller F, Ogata H, Miura I, Shikama Y, Yabe H, Onoue S, Fromm MF, Kimura J, Misaka S. Role of (-)-epigallocatechin gallate in the pharmacokinetic interaction between nadolol and green tea in healthy volunteers. Eur J Clin Pharmacol. 2018;74(6):775-83.

18. Muchtar E, Blauwet LA, Gertz MA. Restrictive cardiomyopathy. Circ Res. 2017;121(7):819-37.

19. Yancy CW, Jessup M, Bozkurt B, Masoudi FA, McBride PE. 2013 ACCF/AHA guideline for the management of heart failure. J Am Coll Cardiol. 2013;62: e147-239.

20. Colan SD. Hypertrophic cardiomyopathy in childhood. Heart Fail Clin. 2010; 6(4):433-44

21. Ammash NM, Seward JB, Bailey KR, Edwards WD, Tajik AJ. Clinical profile and outcome of idiopathic restrictive cardiomyopathy. Circulation. 2000;101: 2490-6

22. Ligi I, Fraisse A, Chabrol B, Paut O, Bourlon F, Métras D, Bonnet JL, Pellissier JF. Une cardiomyopathie restrictive révélatrice d'une myopathie myofibrillaire. Arch Pediatr. 2003;10(5):432-5.

23. Braunwald $E$. The management of heart failure: the past, the present, and the future. Circulation:Heart Failure. 2008;1(1):58-62.

24. Frazier A, Judge DP, Schulman SP, Johnson N, Holmes KW, Murphy AM. Familial hypertrophic cardiomyopathy associated with cardiac $\beta$-myosin heavy chain and troponin I mutations. Pediatr Cardiol. 2008;29(4):846-50.

25. Carniel E, Taylor MRG, Sinagra G, Di Lenarda A, Ku L, Fain PR, Boucek MM, Cavanaugh J, Miocic S, Slavov D, Graw SL, Feiger J, Zhu XZ, Dao D, Ferguson DA, Bristow MR, Mestroni L. a-Myosin Heavy Chain: A Sarcomeric Gene Associated With Dilated and Hypertrophic. Circulation. 2005;112:54-9.

26. Monasky MM, Ciconte G, Anastasia L, Pappone C. Next generation sequencing and linkage analysis for the molecular diagnosis of a novel overlapping syndrome characterized by hypertrophic cardiomyopathy and typical electrical instability of Brugada syndrome. Circ J. 2016;80:938-49.
27. Ratola A, Silva HM, Guedes A, Mota C, Braga AC, Oliveira D, Alegria A, Carvalho C, Álvares S, Proença E. A novel Noonan syndrome RAF1 mutation: lethal course in a preterm infant. Pediatric Reports. 2015;7:5955.

28. Ko JM, Kim J, Kim G, Yoo H. PTPN11, SOS1, KRAS, and RAF1 gene analysis, and genotype-phenotype correlation in Korean patients with Noonan syndrome. J Hum Genet. 2008;53(11-12):999-1006.

29. Razzaque MA, Nishizawa T, Komoike Y, Yagi H, Furutani M, Amo R, Kamisago M, Momma K, Katayama H, Nakagawa M, Fujiwara Y, Matsushima M, Mizuno K, Tokuyama M, Hirota H, Muneuchi J, Higashinakagawa T, Matsuoka R. Germline gain-of-function mutations in RAF1 cause Noonan syndrome. Nat Genet. 2007;39(8):1013-7.

30. Nihoyannopoulos P, Dawson D. Restrictive cardiomyopathies. Eur J Echocardiogr. 2009;10(8):i23-33.

31. Liu X, Zhang L, Pacciulli D, Zhao J, Nan C, Shen W, Quan J, Tian J, Huang X. Restrictive cardiomyopathy caused by troponin mutations: application of disease animal models in translational studies. Front Physiol. 2016;7:629.

32. Mogensen J, Kubo T, Duque M, Uribe W, Shaw A. Idiopathic restrictive cardiomyopathy is part of the clinical expression of cardiac troponin I mutations. J Clin Invest. 2003;111:209-16.

33. van den Wijngaard A, Volders P, Van Tintelen JP, Jongbloed JDH, van den Berg MP, Lekanne Deprez RH, Mannens MMAM, Hofmann N, Slegtenhorst M, Dooijes D, Michels M, Arens Y, Jongbloed R, Smeets BJM. Recurrent and founder mutations in the Netherlands: cardiac troponin I (TNNI3) gene mutations as a cause of severe forms of hypertrophic and restrictive cardiomyopathy. NETH HEART J. 2011;19(7-8):344-51.

34. Gallego-Delgado M, Delgado JF, Brossa-Loidi V, Palomo J, Marzoa-Rivas R, Perez-Villa F, Salazar-Mendiguchia J, Ruiz-Cano MJ, Gonzalez-Lopez E, Padron-Barthe L, Bornstein B, Alonso-Pulpon L, Garcia-Pavia P. Idiopathic restrictive cardiomyopathy is primarily a genetic disease. J Am Coll Cardiol. 2016;67(25):3021-3.

35. Qiu X, Liu W, Hu D, Zhu T, Li C, Li L, Guo C, Liu X, Wang L, Zheng H, Wang C, Diao Q, Shi D, Zhan P, Deng Y, Liu K, Wang Y, Liu B, Liu H, Zhang L. Mutations of Plakophilin-2 in Chinese with Arrhythmogenic right ventricular dysplasia/cardiomyopathy. Am J Cardiol. 2009;103(10):1439-44.

36. Artz G, Wynne J. Restrictive cardiomyopathy. Current Treatment Options in Cardiovascular Medicine. 2000;2:431-8.

37. Aus Dem Siepen F, Bauer R, Aurich M, Buss S, Steen H, Altland K, Kristen A, Katus HA. Green tea extract as a treatment for patients with wild-type transthyretin amyloidosis: an observational study. Drug Des Devel Ther. 2015;9:6319-25

38. Hunstein W. Epigallocathechin-3-gallate in AL amyloidosis: a new therapeutic option? BLOOD. 2007;110(6):2216

39. Mereles D, Wanker EE, Katus HA. Therapy effects of green tea in a patient with systemic light-chain amyloidosis. Clin Res Cardiol. 2008;97:341-4.

40. Tobushi T, Nakano M, Hosokawa K, Koga H, Yamada A. Improved diastolic function is associated with higher cardiac output in patients with heart failure irrespective of left ventricular ejection fraction. J Am Heart Assoc. 2017:6(3):e3389.

41. Adhyapak S, Parachuri V. Impact of surgical ventricular restoration on stroke volume: surgical fine-tuning of the relationship between end-diastolic volume and stroke volume. J Thorac Cardiovasc Surg. 2011;141(6):1553-4.

42. Karlstrom P, Dahlstrom U, Boman K, Alehagen U. Responder to BNP-guided treatment in heart failure. The process of defining a responder. Scand Cardiovasc J. 2015:49(6):316-24

43. Di Somma S, Marino R, Zampini G, Magrini L, Ferri E, Shah K, Clopton P, Maisel AS. Predictive value for death and rehospitalization of 30-day postdischarge B-type natriuretic peptide (BNP) in elderly patients with heart failure. Sub-analysis of Italian RED study. Clin Chem Lab Med. 2015;53(3):507.

44. Sarma DN, Barrett ML, Chavez ML, Gardiner P, Ko R. Safety of green tea extracts. Drug Saf. 2008;31(6):469-84. 